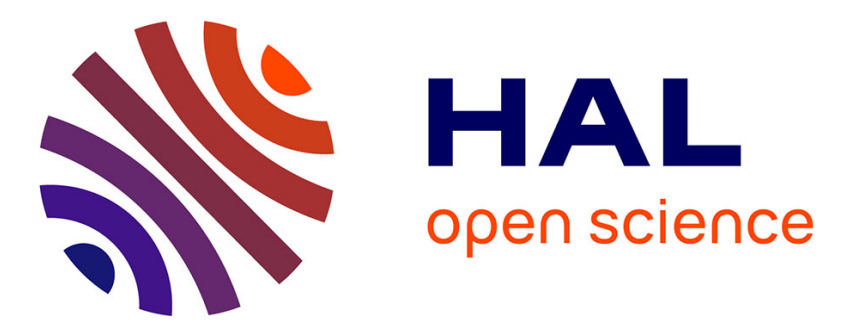

\title{
Streamer and Breakdown Phenomena Under Step and Lightning Impulses in Various Hydrocarbon Liquids
}

\author{
André Denat, Olivier Lesaint, Francis Mc Cluskey
}

\section{To cite this version:}

André Denat, Olivier Lesaint, Francis Mc Cluskey. Streamer and Breakdown Phenomena Under Step and Lightning Impulses in Various Hydrocarbon Liquids. IEEE Conference on Electrical Insulation and Dielectric Phenomena, (CEIDP), Oct 2014, Des Moines, United States. 10.1109/CEIDP.2014.6995862 . hal-01282698

\section{HAL Id: hal-01282698 \\ https://hal.science/hal-01282698}

Submitted on 10 Feb 2022

HAL is a multi-disciplinary open access archive for the deposit and dissemination of scientific research documents, whether they are published or not. The documents may come from teaching and research institutions in France or abroad, or from public or private research centers.
L'archive ouverte pluridisciplinaire HAL, est destinée au dépôt et à la diffusion de documents scientifiques de niveau recherche, publiés ou non, émanant des établissements d'enseignement et de recherche français ou étrangers, des laboratoires publics ou privés.

\section{다)(1) $(5$}

Distributed under a Creative Commons Attribution - NonCommerciall 4.0 International 


\title{
Streamer and Breakdown Phenomena Under Step and Lightning Impulses in Various Hydrocarbon Liquids
}

\author{
A. Denat, O. Lesaint and F. Mc Cluskey \\ Grenoble Electrical Engineering Laboratory (G2Elab) \\ Univ. Grenoble Alpes, G2Elab, F-38000 Grenoble, France \\ CNRS, G2Elab, F-38000 Grenoble, France
}

\begin{abstract}
In this study, measurements of breakdown voltages and time to breakdown are carried out over a large range of gap distances (from 2 to $20 \mathrm{~cm}$ ) versus liquid nature. Measurements were obtained in divergent field, with either step or lightning impulse voltages. Non-polar hydrocarbon liquids with different chemical structures are studied: saturated, aromatic, polyaromatic, mineral oils. Large effects of liquid nature, gap distance, and voltage waveform, are seen. In very long gaps with lightning impulse, streamers with a low propagation velocity (a few $\mathrm{km} / \mathrm{s}$ ) are quenched, due to the rapidly decaying voltage. Breakdown can be only due to fast streamers, which appear in very different conditions according to the liquid nature. Measurements under step voltage provide a useful basis to interpret the complex variations obtained under lightning impulse. These results also show that testing and comparing liquids under lightning impulse in short gaps (a few $\mathrm{cm}$, such as in standard tests) does not provides data relevant for the actual behavior of liquids under very high voltage.
\end{abstract}

\section{INTRODUCTION}

Breakdown measurements in liquids at large gaps and high voltage (several hundred $\mathrm{kV}$ ) are important to assess the behavior of liquids in conditions relevant to high voltage transformers. Due to the large non-linearity of breakdown processes when distance and voltage are increased, it is rather uncertain to conclude about the high voltage properties of a particular liquid on the basis of data obtained in small gaps (a few centimeters). A typical example is provided by esters. In conditions of standard tests under lightning impulse voltage (25 mm gap in IEC 60897 or ASTM D3300 standards), breakdown properties of esters compare with mineral oil. However, mineral oil shows much better properties when the gap distance is increased to $10 \mathrm{~cm}[1,2]$. In esters, streamers switch to fast propagation modes at voltages much lower than in transformer oil.

Previous measurements in large gaps (longer than about $5 \mathrm{~cm}$ ) were obtained either with lightning impulses (LI) in mineral oil and esters [1-3], or with "Step" voltages (with fast rise and long durations) in mineral oil [4,5], esters [6], refined white oils and cyclohexane containing additives [7-9], aromatic and polyaromatic hydrocarbons [10]. Step voltage is favorable to interpret measurements (the voltage remains constant while streamers propagate). Interpretation of data obtained with lightning impulses is less easy since voltage varies as the streamer propagates. On the other hand, breakdown voltage measurements with LI are more representative of apparatus testing conditions than Step.
In this paper, breakdown properties are investigated in a variety of liquids under lightning impulses versus gap distances up to $20 \mathrm{~cm}$. Results obtained in the same liquids with step voltage are used to interpret lightning impulse measurements.

\section{EXPERIMENTAL TECHNIQUES AND MATERIALS}

\section{A. Breakdown measurements with lightning and step impulses}

Breakdown measurements under $1.2 / 50 \mu$ s impulse were carried out in a point - sphere geometry. The grounded sphere electrode had a $2 \mathrm{~cm}$ diameter, and the point electrode (made of brass) had a $300 \mu \mathrm{m}$ tip radius of curvature. Voltage was increased by $5 \mathrm{kV}$ steps until breakdown occurred. The value of breakdown voltage $V_{b}^{L I}$ was noted (crest value of the lightning impulse), as well as the time to breakdown $t_{b}{ }^{L I}$. The origin of time $t=0$ was arbitrarily chosen when $V=0.5 \times V_{b}^{L I}$ during the voltage rise. This procedure was repeated at least five times, and quoted values of $V_{b}{ }^{L I}$ and $t_{b}{ }^{L I}$ on figures are average values.

Measurements were also carried out in point-plane gaps with "step" voltages with a fast rise and long decay time $(0.4 / 1400$ $\mu \mathrm{s})$, according to methods identical to those presented in [4]. Due to the long tail of the impulse, the voltage drop during the propagation of streamers is negligible $(\leq 10 \%)$, even when long gaps up to $20 \mathrm{~cm}$ are used (corresponding to maximum times to breakdown about $100 \mu \mathrm{s}$ ). In contrast, with the 1.2/50 $\mu \mathrm{s}$ wave, voltage shows a large decrease during streamer propagation in identical conditions.

\section{B. Liquids}

Experiments were carried out with 10 non-polar liquids, divided into several distinct chemical groups:

- aromatic hydrocarbons (containing a single benzene ring): phenylxylylethane (PXE), isopropylbiphenyl (IPB), monoand di- benzyltoluene (BT01, BT02), and 75/25\% mixture (BT06). These synthetic aromatic liquids are typical basic constituents of commercial capacitor liquids;

- a polyaromatic hydrocarbon with two benzene rings: diisopropylnaphtalene (IPN);

- a ramified alkylbenzene: dodecylbenzene (DDB);

- paraffinic (PMO) and naphtenic (NMO) mineral oils;

- a refined white oil: Marcol 52 (WO); 
- a polyolefin: polybutene (PB).

All liquids were filtered, degassed and dryed prior to experiments (water content $<10 \mathrm{ppm}$ ).

For clarity, a typical selection of results obtained in these liquids will be presented below. In all conditions, positive breakdown voltages (i.e. obtained with positive voltage applied to the point) were lower than negatives. Thus, only results in positive polarity will be presented here.

\section{BREAKDOWN MEASUREMENTS WITH 1.2/50 $\mu \mathrm{s}$ LIGHTNING IMPULSES}

\section{A. Breakdown voltage $V_{b}^{L I}$ versus gap distance}

Figure 1a and $1 \mathrm{~b}$ shows measurements of the breakdown voltage $V_{b}^{L I}$ with a positive point versus gap distance $d$, in several liquids. On these figures, we have also added for comparison measurements reported in a natural ester NE [2]. When the gap distance is increased, the increase of breakdown voltage is rather different according to liquids. Liquids with nearly identical breakdown voltages versus gap can be classified into several "groups":

I: natural ester NE: the lowest breakdown voltages over the whole distance range;

II: mono-aromatic liquids: BT06 and IPB (identical behavior were observed in PXE, BT01, BT02);

III: White Oil and DDB (identical behavior was observed in IPN, with a slightly higher $V_{b}^{L I}$ at short distance);

IV: Mineral oils and polybutene PB

On figure 1, two typical plot shapes can be observed.

Groups I and II (fig. 1a): $V_{b}^{L I}$ increases smoothly with distance, but values are shifted by about $+60 \mathrm{kV}$ in monoaromatic liquids at all distances. Among all liquids studied, mono-aromatic liquids of group II show the highest $V_{b}^{L I}$ in short gaps $<5 \mathrm{~cm}$;

Groups III and IV (fig. 1b): These liquids get nearly identical $V_{b}{ }^{L I}$ in the shortest gaps $(2 \mathrm{~cm})$, and a comparable rate of increase of $V_{b}{ }^{L I}(34 \mathrm{kV} / \mathrm{cm})$ up to about $7 \mathrm{~cm}$. Above some critical distance $d_{\text {crit }}$ (group III $\approx 7 \mathrm{~cm}$, group IV $\approx 12 \mathrm{~cm}$ ) the rate of increase suddenly drops (about $9 \mathrm{kV} / \mathrm{cm}$ for group III).

The ranking of liquids markedly changes according to the gap distance, as illustrated by typical examples: the ester is identical to mineral oil up to $\mathrm{d}=3 \mathrm{~cm}$, but much lower at $\mathrm{d}=$ $20 \mathrm{~cm}(-58 \%)$. The aromatic BT is much higher than mineral oil at $\mathrm{d}=3 \mathrm{~cm}(+66 \%)$, and much lower at $\mathrm{d}=20 \mathrm{~cm}(-55 \%)$.

\section{B. Time to breakdown $t_{b}^{L I}$ and average propagation velocity}

Figure 2 shows measurements of the time to breakdown $t_{b}{ }^{L I}$ (average values) versus gap distance $d$. The shapes of plots considerably depend on the liquid nature. In liquids of groups III and IV, the time to breakdown first increases with distance, and sharply drops above the critical distance $d_{\text {crit }}$ observed on figure 1a. In liquids of group II, the time to breakdown is nearly constant ( 2 to $4 \mu \mathrm{s}$ ) whatever the distance (except at 1 $\mathrm{cm}$ in BT).

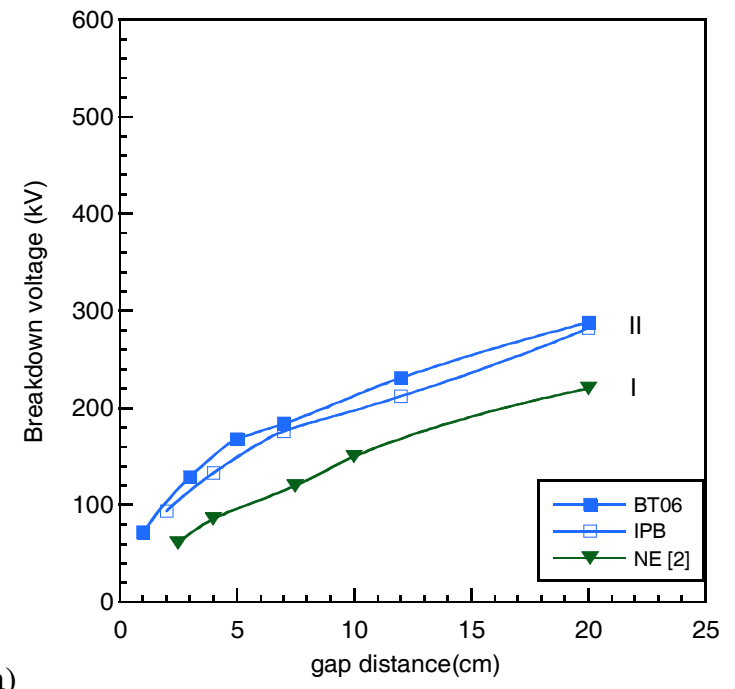

a)

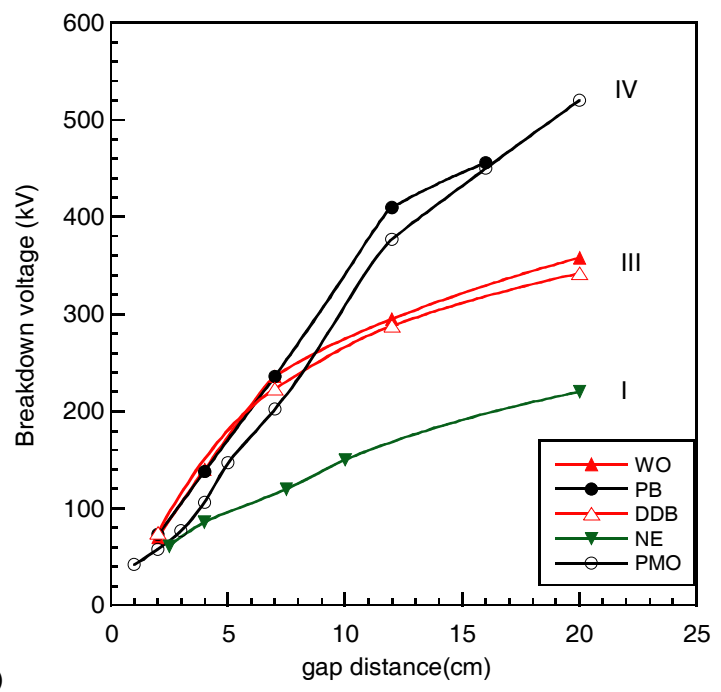

Fig. 1. Breakdown voltage $V_{b}^{L I}$ under lightning impulse versus gap distance in various liquids. NE results come from [2].

The total time to breakdown $t_{b}^{L I}$ includes:

- a statistical streamer "inception delay" $t_{i}$ that strongly depends on the tip radius and voltage;

- the streamer propagation time $t_{p}$ across the gap distance $d . t_{p}$ can result from the successive propagation of different "modes" with different velocities [4].

Since a sharp tip radius and voltages well above the streamer minimum inception voltage are used, the inception delay $t_{i}$ can be neglected. From values of $t_{b}{ }^{L I}$, an average "breakdown velocity" $v_{b}{ }^{L I}=d / t_{b}{ }^{L I}$ can be calculated (figure 3 ), and it mainly represents the average streamer propagation velocity from the point to the ground electrode.

In all liquids, a velocity about $1-3 \mathrm{~km} / \mathrm{s}$ is observed with the lowest gaps and voltage investigated. This velocity is typical for " 2 nd mode" positive streamers. Above some critical distance, the breakdown velocity suddenly increases, and reaches very high values, typical of $3^{\text {rd }}$ and $4^{\text {th }}$ modes observed above the "acceleration voltage" [4 -6]. 


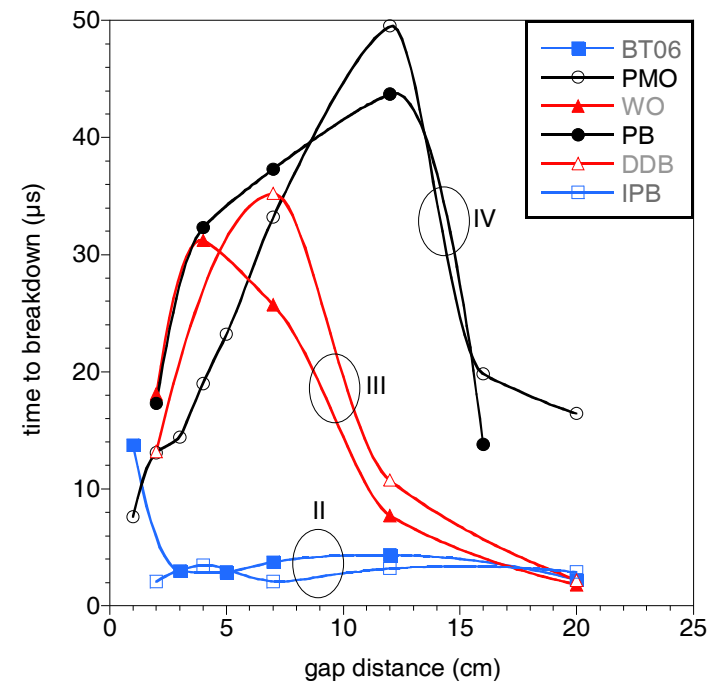

Fig. 2. Time to breakdown $t_{b}^{L I}$ voltage under lightning impulse versus gap distance in various liquids.

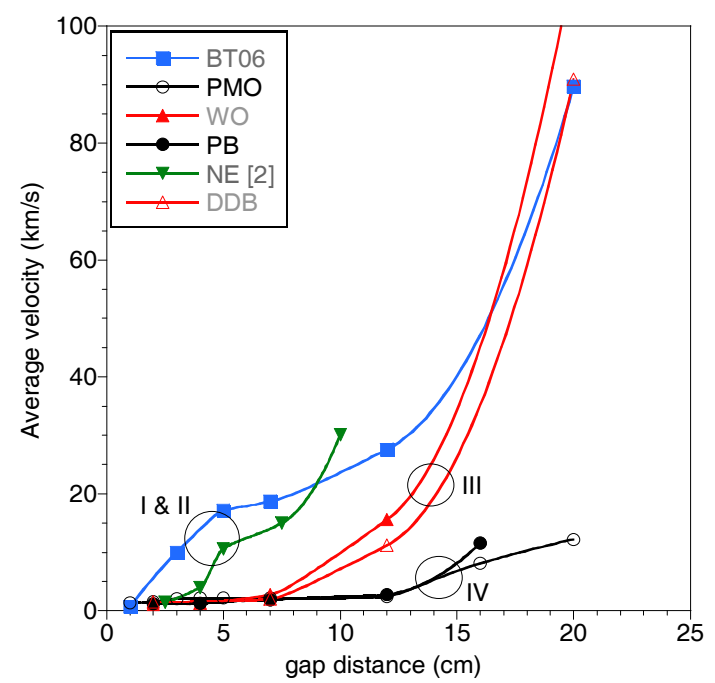

Fig. 3. Average breakdown velocity $v_{b}{ }^{L I}$ under lightning impulse versus gap distance in various liquids. NE results come from [2].

\section{COMPARISON WITH BREAKDOWN MEASUREMENTS UNDER STEP IMPULSES}

The comparison with breakdown under step voltage is very useful to better understand measurements obtained with lightning impulse. Under step voltage, the voltage remains constant during propagation, and the measured breakdown voltage $V_{b}{ }^{S}$ has a simple and clear meaning: it represents the minimum voltage required for propagation up to breakdown. Below $V_{b}^{S}$ streamers cannot propagate up to the grounded electrode, they stop and no breakdown occurs.

Figure 4 shows the comparison of breakdown voltages (a) and breakdown velocities (b) recorded in mineral oil under lightning and step voltages. We have also added for comparison values of the instantaneous breakdown voltage $V_{i}$ measured at the instant of breakdown under lightning impulse. a)

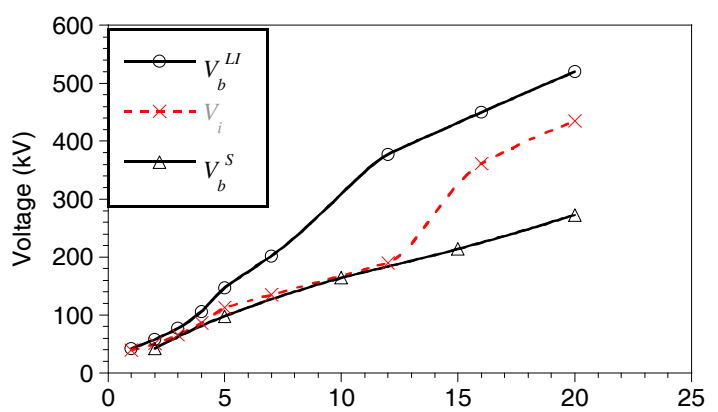

b)

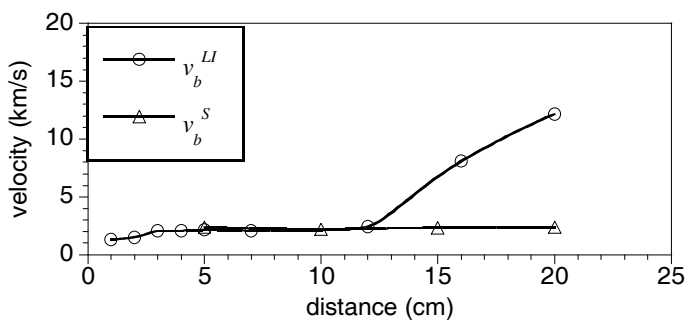

Fig. 4. a: comparison of breakdown voltages in mineral oil under lightning impulse $\left(V_{b}{ }^{L I}\right)$, Step $\left(V_{b}{ }^{S)}\right.$, and instantaneous LI breakdown voltage $\left(V_{i}\right)$. b: comparison of breakdown velocity $v_{b}$ under lightning and step.

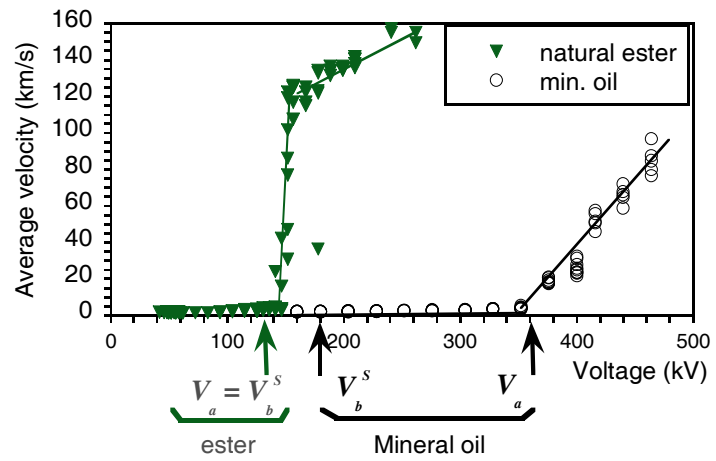

Fig. 5. Streamer average velocity measured under step voltage in mineral oil [4] and natural ester [6] in a $10 \mathrm{~cm}$ gap. $V_{b}^{S}$ : breakdown voltage, $V_{a}$ : acceleration voltage.

Step and LI breakdown voltages are quite close in small gaps $(\leq 2 \mathrm{~cm})$, but the difference rapidly increases when $d$ is increased. This is logical, since under LI voltage drops during propagation. A larger LI crest voltage must be applied to induce breakdown, in such a way that the instantaneous voltage does not drop below the minimum propagation voltage $\left(V_{b}^{S}\right)$ before the streamer reaches the electrode. It is very interesting and logical to observe that under LI, the instantaneous breakdown voltage $V_{i}$ closely corresponds to the minimum propagation voltage $V_{b}^{S}$ (distances up to $12 \mathrm{~cm}$ ).

In these conditions, the average breakdown velocity remains constant and identical under step and LI $(2 \mathrm{~km} / \mathrm{s}$, figure $4 \mathrm{~b})$. This also agrees with previous measurements carried out under step with large overvoltage (figure 5) [4]. This figure shows that the velocity remains constant when voltage is raised well above $V_{b}^{S}$, up to the "acceleration voltage" $V_{a}$. In mineral oil, $V_{a}$ is about twice as high as $V_{b}^{S}$. 
a)
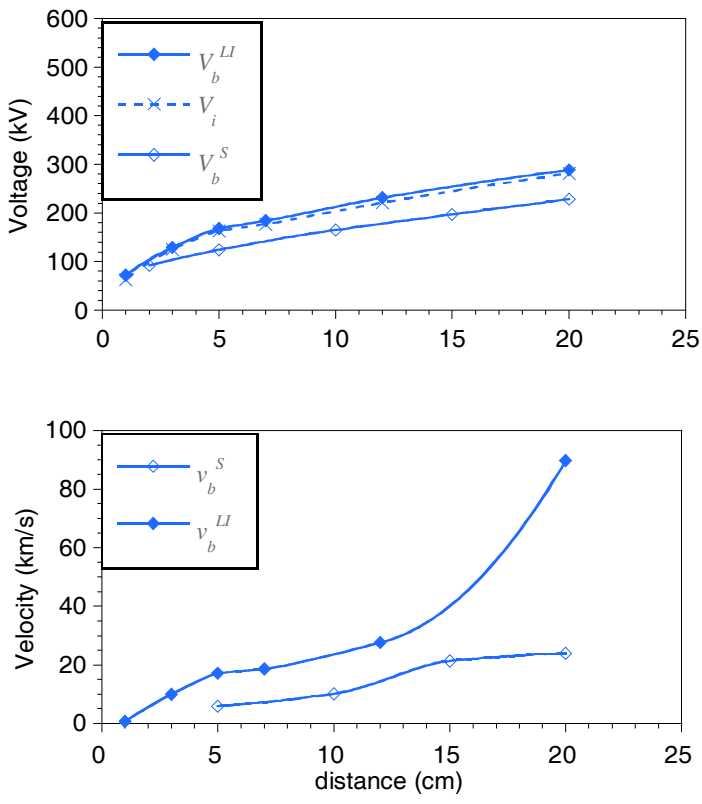

b)

Fig. 6. a: comparison of breakdown voltages in BT06 under lightning impulse $\left(V_{b}{ }^{L I}\right)$, Step $\left(V_{b}^{S)}\right.$, and instantaneous LI breakdown voltage $\left(V_{i}\right)$. b: comparison of breakdown velocity $v_{b}$ under lightning and step.

Under LI, when the crest value $V_{b}{ }^{L I}$ becomes higher than $V_{a}$ (at large gaps), an acceleration of streamers logically occurs (figure 4b). This is observed above $d=12 \mathrm{~cm}$, corresponding to $V_{b}^{L I}=380 \mathrm{kV}$, i.e. a value in good agreement with the measured acceleration voltage $\left(V_{a}=370 \mathrm{kV}\right.$ at $d=10 \mathrm{~cm}$, see figure 5).

In other liquids such as esters, breakdown and acceleration voltages under step are nearly identical, and streamer acceleration is very steep (figure 5). Logically, under LI the breakdown voltage $V_{b}^{L I}$ is nearly identical to the acceleration voltage, as previously concluded in [2].

A nearly identical situation is observed in aromatic liquids such as BT06 (figure 6). In this liquid, the breakdown under LI is due to fast streamers $\left(v_{b}>10 \mathrm{~km} / \mathrm{s}\right)$ with gaps larger than $1 \mathrm{~cm}$. Only a small difference exists between lightning and step impulse voltage.

\section{DISCUSSION AND CONCLUSIONS}

The measurements carried out under lightning impulse allow us to derive several conclusions concerning the interpretation of breakdown measurements, the influence of liquid composition, and testing methods of liquids.

Breakdown under lightning impulse (LI) in large gaps evidence much greater differences between liquids compared to step measurements [10]. In large gaps (typically $20 \mathrm{~cm}$ ), breakdown under LI requires propagation of fast streamers, and the breakdown voltage $V_{b}^{L I}$ is close to the acceleration voltage $V_{a}$, that widely varies according to the liquid nature. These differences are not seen in short gaps (a few $\mathrm{cm}$ ), at which slower " $2^{\text {nd }}$ mode" streamers can propagate to breakdown. As a main consequence, testing liquids in short gaps with LI (such as in standard tests) does not provide a classification of liquids relevant to their behavior at higher voltage.

Concerning the influence of liquid nature on behavior at high voltage, it is generally accepted that mineral oils get superior performance compared to many other liquids, due to the presence of aromatic compounds that produce a higher "resistance" to fast streamers [7-9]. It is however interesting to observe that pure aromatic liquids (such as capacitor liquids) provide a weak performance at high voltage, and that a pure non-aromatic liquid (polybutene) has nearly equivalent properties as mineral oil in large gaps. At much lower distances and voltage, this pure liquid also has the same characteristic features as mineral oils and liquids containing low ionization potential additives: a low propagation threshold of " 2 nd mode" streamers, and a marked tendency to form branches [10]. This liquid probably has specific electronic properties which are not known. Their study could constitute an interesting way to better understand the correlation between liquid structure and high voltage properties.

\section{ACKNOWLEDGMENT}

The authors would like to acknowledge Mr P. Jay and Mrs N. Berger, from the former ELF Atochem / Arkema company, for their help and support for this study.

\section{REFERENCES}

[1] L. Rongsheng et al. "Ester fluids as alternative for mineral oil: The difference in streamer velocity and LI breakdown voltage", IEEE. Conf. Electr. Insul. Diel. Phen. (CEIDP), Virginia, p.543, 2009.

[2] Q. Liu and Z.D. Wang, "Streamer characteristic and breakdown in synthetic and natural ester transformer liquids under standard lightning impulse voltage", IEEE Trans. Diel. Elec. Insul., vol. 18, p. 285, 2011.

[3] Y. Kamata and Y. Kako, "Flashover characteristics of extremely long gaps in transformer oil under non-uniform conditions", IEEE Trans. Electr. Insul., Vol. 15, $N^{\circ} 1$, pp. 18-26, 1980.

[4] O. Lesaint and G. Massala, "Positive streamer propagation in large oil gaps: experimental characterization of propagation modes", IEEE Trans. Dielectr. Electr. Insul., Vol.5, No.3, pp.360-370, 1998

[5] D. Linhjell, L. Lundgaard and G. Berg, "Streamer Propagation under Impulse Voltage in Long Point-Plane Oil Gaps", IEEE Trans on Diel and Elec Insul, vol. 1, $n^{\circ} 3$, p. 447-458, 1994.

[6] C. Tran Duy, O. Lesaint, A. Denat, N. Bonifaci, "Streamer Propagation and Breakdown in Natural Ester at High Voltage", IEEE Trans on Diel. and Elec. Insul., Vol. 16, Issue 6, p. 1582, 2009.

[7] O. Lesaint and M. Jung, "On the relationship between streamer branching and propagation in liquids: influence of pyrene in cyclohexane.", J. Phys. D: Appl. Phys, 33, pp. 1360-1368, 2000

[8] D. Linhell et al., "Streamers in long point-plane gaps in cyclohexane with and without additives under step voltage", 17th. Int. Conf. on Diel. Liq. (ICDL), IEEE, Trondheim (Norway), June 26-30, 2011.

[9] N.V. Dung et al., "Influence of impurities and additives on positive streamers in paraffinic model oil", IEEE Trans. Dielectr. Electr. Insul., Vol.19, No.5, pp.1593-1603, 2012.

[10] O. Lesaint, A. Denat, F. Mc Cluskey, "Positive streamers in short and large gaps in hydrocarbons of various chemical natures", 18th. Int. Conf. on Diel. Liq. (ICDL), IEEE, Bled (Slovenia), June30-July3, 2014. 